\title{
Cultura Cultura
}

Revista de Historia Teoria das ldeaias - Revista de História e Teoria das Ideias

Vol. 30 | 2012

A justiça na Antiguidade

\section{O discurso da justiça em Jeremias 1-25}

profetismo, realeza e crítica social

The discourse of justice in Jeremiah 1-25: prophecy, kingship and social criticism

João Pedro Vieira

\section{OpenEdition}

Journals

Edição electrónica

URL: http://journals.openedition.org/cultura/1569

DOI: 10.4000 /cultura. 1569

ISSN: 2183-2021

Editora

Centro de História da Cultura

Edição impressa

Data de publição: 1 Dezembro 2012

Paginação: $77-88$

ISSN: 0870-4546

Refêrencia eletrónica

João Pedro Vieira, «O discurso da justiça em Jeremias 1-25 », Cultura [Online], Vol. 30 | 2012, posto online no dia 15 setembro 2014, consultado a 19 abril 2019. URL : http://journals.openedition.org/ cultura/1569; DOI : 10.4000/cultura.1569

Este documento foi criado de forma automática no dia 19 Abril 2019.

(c) CHAM - Centro de Humanidades / Centre for the Humanities 


\title{
O discurso da justiça em Jeremias
}

\section{$1-25$}

\author{
profetismo, realeza e crítica social
}

The discourse of justice in Jeremiah 1-25: prophecy, kingship and social criticism

\author{
João Pedro Vieira
}

\section{Coordenadas conceptuais: pensar a justiça}

1 A justiça representa, nas suas diversas manifestações históricas e concretizações lexicais e semânticas, um dos princípios mais importantes no pensamento e governo das sociedades humanas. Intrinsecamente ligado ao domínio da moralidade - ou seja, de um universo socialmente construído de princípios e normas que regem, de forma tendencialmente vinculativa, o comportamento dos membros de uma determinada comunidade, neles suscitando as noções de obrigação e dever -, o princípio da justiça reveste-se de uma natureza eminentemente social, pressupondo a existência de um sistema de relações cujas características definem o estatuto do indivíduo na comunidade e determinam o que lhe é exigível e, simultaneamente, o que lhe é devido. ${ }^{1}$

2 Nesta acepção, o princípio da justiça aproxima-se da conceptualização jurídica que o Digesto (I.1.10.1 pr.) atribuiu a Ulpiano (m. 223/224 d.C.), segundo a qual a justiça consistia em dar a cada um o seu direito (ius suum cuique tribuendi), ${ }^{2}$ i.e., dar a cada um aquilo que lhe é devido, a que tem direito. À luz desta síntese, a justiça apresenta-se como uma estrutura formal de regulação da interacção social que procura e serve a preservação da ordem sociopolítica vigente, qualquer que seja a sua manifestação e conteúdo próprio. Reconhece por isso a assimetria essencial que rege as relações sociais, a existência de hierarquias e desníveis de poder social e riqueza. 


\section{0 conceito de justiça no Próximo Oriente antigo: justiça, ordem e realeza}

3 Também no Próximo Oriente antigo o conceito de justiça, nas suas diversas acepções (ac. kittum, mêšarum; eg. maât; heb. mišpāț, dîn, ședeq, ședāqāh, mêšārîm), se revelou um princípio constitutivo do pensamento pré-clássico sobre a ordem social. Assentando numa estrutura conceptual básica bastante similar à acima delineada, a justiça constituía um atributo ontologicamente transversal que exprimia a capacidade ou poder de garantir e restabelecer a ordem divinamente criada e o lugar de cada um. Neste sentido, a formulação do conceito implicava necessariamente a confluência dos planos divino e humano da existência, mas igualmente a percepção de que a esfera da ordem coexistia, em situação de tensão e perpétuo conflito, com uma esfera do caos. Nesta perspectiva de ordem totalizante do universo, a conceptualização da justiça assumiu porventura a sua manifestação mais evidente e complexa no Egipto Antigo, através do conceito de maât. ${ }^{3}$ Sintetizando as dimensões social (humana) e cósmica da justiça, o conceito de maât exprimia uma vivência unificadora e integradora, socialmente baseada, da experiência do mundo, sob a protecção da monarquia faraónica; uma prática de uma solidariedade comunicativa e prescritiva. ${ }^{4}$

4 Neste sentido, o rei era representante e garante de uma dupla ordem. Instância de mediação privilegiada entre os planos divino e humano, filho de Deus e ungido (Sl. 2:7; 45:8; 89:21, 27-28; 132:10, 17), o rei é investido do poder de dominar o caos (Sl. 89:26. Carta de Nûr-Sîn a Zimrî-Lîm, A.1968) ${ }^{5}$ e o desempenho das suas funções afecta directamente a estabilidade da ordem natural (Epopeia de Kirta 1.19 I 38-46). ${ }^{6}$ Simultaneamente, o rei afirmava-se como paladino da justiça, protector e defensor do direito dos pobres, fracos e oprimidos, da viúva, do órfão e do estrangeiro (Sl. 72:1-2, 4, 12-14. Carta de Nûr-Sîn a Zimrî Lîm A.1121 + A.2731. ${ }^{7}$ Código de Hammurabi, Prólogo, I 28-49; V 14-24). ${ }^{8}$ A autoridade régia e o regime monárquico significavam o primado e a vitória permanentemente reafirmada da justiça enquanto (re)ordenação das res diuinae atque humanae sobre a terra.

\section{Justiça social, realeza e profetismo na tradição veterotestamentária}

5 Todavia, se o topos da justiça, particularmente na sua vertente social, ocupa uma posição de relevo no discurso de legitimação e apologia da realeza, a prática aparenta demonstrar, não raro, as francas limitações da implementação desse princípio. De facto, a literatura profética veterotestamentária apresenta uma prolixidade notável de situações de conflito sociopolítico aberto entre alguns profetas e a realeza, assim como contra outros grupos sociais de elite (sacerdotes, profetas, oficialato régio e os investidos de poderes judiciais), desdobrando-se em manifestações críticas de denúncia e condenação de uma prolixidade de injustiças sociais, da política interna e externa, e de matérias religiosas (e.g. Os. 5:1-3, 10-13; 7:3-7. Mq. 2:1-5, 3. Is. 10:1-4. Jr. 26:8-11). ${ }^{9}$

6 É possível que as proporções do conflito, que aparentam ter atingido momentos de grande tensão e agressividade (e.g. Am. 3:14-15. Jr. 22:13-19; 28), tenham sido de alguma forma hiperbolizadas pelas perspectivas ideológicas/teológicas, e suas categorias interpretativas, que enformaram o extenso e multigeracional trabalho de edição/ 
redacção das diversas tradições textuais que perfazem o corpus profético veterotestamentário. ${ }^{10}$ Efectivamente, a tradição veterotestamentária apresenta casos de estreita cooperação entre profetismo e política (caso de Natan, 2 Sm. 7; 12:1-15. 1 Rs. 1:1-31). Neste sentido, à semelhança do que ocorreria com o profetismo mariota, ${ }^{11}$ é provável que o profetismo hebraico procurasse funcionar de alguma forma como instância de aconselhamento, advertência e vigilância da acção régia com o propósito de evitar ou corrigir situações de injustiça para com a sociedade humana ou divina, que colocassem em causa a eficácia da realeza enquanto garante do equilíbrio cósmico, divinamente criado e, por esse motivo, intrinsecamente justo.

7 De acordo com a tradição textual homónima, a intervenção profética de Jeremias na esfera pública hierosolimita pautou-se por um discurso profundamente contestatário de tipo sócio-religioso que terá compreendido manifestações de vincada hostilidade para com a condução da política interna e externa de Judá, e a própria figura régia, particularmente durante o reinado de Joaquim (610/609-598 a. C.). ${ }^{12}$ A complexidade da história redaccional da tradição jeremiana, assim como os problemas envolvidos na datação genérica dos textos e na caracterização dos ambientes sociológicos e ideológicos/ teológicos de produção - ou seja, até que ponto são os textos representativos da intervenção profética de Jeremias -, levantam dificuldades significativas à determinação segura das posições político-religiosas do profeta. ${ }^{13}$

Desta forma, no âmbito das limitações supramencionadas e tomando por repositório heurístico o bloco textual onde se concentram os materiais pretensamente mais antigos e menos editados (Jr. 1-25), como se manifesta o conceito de justiça, em especial na sua acepção social, ao longo do discurso profético jeremiano? Que léxico e que contextos semânticos dominam a utilização desse conceito? Qual a importância que o conceito de justiça assume no discurso do profeta?

\section{0 conceito de justiça no discurso profético de Jeremias}

\subsection{O léxico da justiça}

9 No campo semântico da justiça, mišpāt afigura-se o termo mais frequente, ocorrendo 32 vezes ao longo da versão massorética de Jeremias, seis das quais para formar a conhecida expressão mišpāt ûș ${ }^{e} \bar{a} q \bar{a} h$ (Jr. 4:2; 9:23; 22:3, 15; 23:5; 33:15a). O termo mišpāṭ, muito frequente nos Sl., exprime nas suas diversas ocorrências as noções semanticamente contíguas de "justiça" (Jr. 10:24; 22:3, 13, 15 23:5), “julgamento" (5:28; 7:5; 21:12; 26:11, 16; $33: 15)$, “sentença" (12:1; 39:5; 49:12; 51:9; 52:9), “direito" (32:7-8) e até “ordem" (8:7). No entanto, são escassas as ocorrências do verbo correspondente, šāpāṭ (2:35; 5:28; 11:20; 25:31). Para além de šāpāt e seus derivados, a tradição jeremiana regista a utilização dos termos ș $\underline{d}^{e} \bar{a} q \bar{a} h$ (vd. supra e 33:15b), já referido, ședeq $(11: 20 ; 22: 13 ; 31: 23 ; 50: 7)$ - termos que denotam as ideias de "rectidão", "justiça", "direito", "correcção" - e ainda șaddîq $(12: 1 ; 20: 12 ; 23: 5)$, adjectivo com o significado análogo de "recto", "justo" ou ainda "legítimo". De entre o repertório lexical conotado com a justiça, cabe ainda mencionar o substantivo dîn e o verbo correspondente dan (5:28;21:12; 22:16), lexemas que traduzem respectivamente a noção de "julgamento", “juízo", “causa”, no primeiro caso, e a acção de “julgar”, “defender a causa”, "pronunciar juízo”, no segundo caso. ${ }^{14}$ 


\subsection{0 discurso da justiça social: análise de textos}

10 Em 5:1-9, Jeremias, interpelando retoricamente os seus interlocutores, critica a infidelidade e iniquidade de toda a população de Jerusalém perante Yahweh: ninguém pratica a justiça (mišspăț) ou sequer procura a fidelidade/confiança ('ěmûnāh), valores constitutivos da moral comunitária e cuja ausência explica que os humildes (dallîm) perjurem em nome de Yahweh e desconheçam o seu caminho e o julgamento, ou direito ( kî lō $\bar{o}^{c} y \bar{a} d^{e}$ 'û derek yhwh mišpāt 'élōhêhem). No entanto, também os poderosos (haggedōlîm), sobre os quais recaía a obrigação de conhecer e praticar o caminho e o direito de Yahweh, se revelam ignorantes quanto a essa matéria, pois quebraram o jugo Yahweh e despedaçaram as suas correntes.

11 Em 5:26-28, Jeremias desenvolve adicionalmente a sua aç̧ão de denúncia das injustiças sociais contra todos os maleficentes (rešăî̀m) que prosperaram e enriquecem imoral/ ilicitamente à custa dos direitos dos seus semelhantes. Apesar das obscuridades textuais de que padece v. $28,{ }^{15}$ o profeta acusa sobretudo os rešā $i ̂ m$ de negligenciarem os direitos dos mais desfavorecidos, inviabilizando a protecção legal que o direito consuetudinário e a realeza lhes reservava: transgridem o direito com as suas más acções (TM), ${ }^{16} \mathrm{ou}$ beneficiam a causa do mal, não julgam a causa do órfão nem o julgamento dos necessitados (mišpāt 'ebyônîm = TM) / viúva (chēras = LXX) (vd. Is. 1:23. Mq. 3:11; 7:3. Dt. 16:18-20). Estarão aqui novamente em causa os poderosos e possidentes de Jerusalém, mas possivelmente também o oficialato régio investido da capacidade de pronunciar julgamento sobre casos de litígio, à semelhança do que ocorre em Jr. 26:10-16, em que os śârê yehûdāh provindos do palácio (wayya ălû mibbêt hammelek) tomaram assento junto à porta nova do templo de Yahweh para julgar Jeremias, estando em causa a sentença de morte (mišpāt māwet) que sacerdotes e profetas pretendiam que lhe fosse aplicada. ${ }^{17}$

12 No contexto do chamado "sermão do templo" (7:2-15), ${ }^{18}$ em que Jeremias reprova explicitamente a confiança inveterada dos hierosolimitas na sacralidade protectora e inviolabilidade de Jerusalém (Jr. 7:4, 10) ${ }^{19}$ o profeta exorta à conversão da conduta moral da população urbana - provavelmente, na sua globalidade, povo e elites -, o que implica apelos ao julgamento imparcial dos homens, como juízo ou discernimento entre duas partes (ta ăšŝu mišspăt bên 'îš ûbên rēéêhû), ${ }^{20}$ à não-opressão do estrangeiro, órfão e viúva (gēer yātôm $w^{e^{\prime}}$ almānāh) e ao não-derramamento de sangue inocente (dām nāqî, Jr. 7:6. Vd. 2:34, dam napešôt 'ebyônîm nequiyîm). Jeremias transmite adicionalmente um cenário de conspurcação da sacralidade do templo e de completo desregramento e perversão das normas morais mais básicas à conservação da ordem social e da justiça em que os hierosolimitas roubam, matam, cometem adultério e prestam falsos testemunhos (7:9). ${ }^{21}$ Efectivamente, de acordo com 9:22-23, a verdadeira sabedoria (hōkmāh), varonia (gebûrāh) e riqueza ('ōśer) residem na compreensão e conhecimento (haśkêl wey yādōa) de Yahweh, deus recto (șaddîq, 12:1), enquanto origem e garante supremo da bondade/fi delidade ( hesed), da justiça e da rectidão no mundo ('ōśeh hesed mišpāṭ ûṣedāqāh bā'āreș).

Porém, é no ciclo contra a realeza (21:11-23:6) que o tom polémico de Jeremias e a temática da justiça social atingem porventura o seu paroxismo na tradição textual jeremiana. Este bloco redaccional transmite imagens francamente negativas e hostis de Joaquin e sobretudo Joaquim, cuja actuação e opções políticas são vivamente reprovadas. No caso de Joaquim, é o governo opressivo e injusto que sobressai pela negligência na administração da justiça, possivelmente também pela utilização de trabalho forçado e 
pelo aumento da pressão fiscal (vd. 2 Rs. 23:33, 35), ${ }^{22}$ e certamente pela insistência numa estratégia de resistência político-militar à hegemonia neobabilónica, linha de actuação não explorada pela invectiva de Jr. 22:13-19.

De forma genérica, o ciclo inicia-se com Jr. 21:11-12, em que a casa de David é exortada a executar a justiça pela manhã (dînû labbōqēr mišpāț) e a livrar o espoliado (gazûl) da mão de quem o oprime ('ôšēq) de forma a prevenir a irrupção da ira divina. 0 dever de zelar pela correcta e retributiva execução da justiça (7:9; 21:11-12) é retomado e redaccionalmente expandido em 22:1-5. ${ }^{23}$ Interpretando a expressão "casa de David", os redactores interpelam o rei mas alargam o universo dos destinatários aos membros da casa real: rei, seus funcionários ('ăbādeykā = TM, mas LXX kai ho oikós sou, "e a tua casa") e demais indivíduos com acesso ao palácio ${ }^{24}$ ('amekā habbā'îm baše ārîm hā'êlleh. Vd. 22:1) são chamados a praticar a justiça e a rectidão (mišpāt ûs $s^{e} d \bar{q} q \bar{a} h$ ), a libertar o espoliado da mão do opressor, a proteger o estrangeiro, órfão e a viúva (gēr yātôm we'almānāh) e a abster-se de derramar sangue inocente (dām nāqî). O cumprimento destas instruções pretensamente divinas, rematado por uma ameaça de destruição, é apresentado como condição indispensável para a conservação da realeza davídida (22:4-5).

Como sugerido, é sobre Joaquim que recaem as críticas mais veementes da polémica jeremiana contra a realeza. A perícope formada por 22:13-19 aparenta referir-se na sua totalidade a este rei. Invertendo o paradigma do rei justo, humano e divino, que Sl. 72 paradigmaticamente expõe, Joaquim é acusado de erguer a sua luxuosa (v. 14-15) casa sobre a injustiça e a iniquidade/ilegitimidade ${ }^{25}$ (bōneh bêtō belō' ședeq, v. 13), invertendo de certa forma a imagem de Sl. 89:15, em que justiça e rectidão constituem o fundamento do trono divino (ședeq ûmišpāt $m^{e} k \hat{n}$ kis'ekā). O profeta exprobra Joaquim por explorar os seus súbditos, sujeitando o povo a trabalhos forçados sem compensação (berēēêhu ya ăbōd hinnām ûpōălô lồ yitten lô, vd. Dt. 24:14-15; Lv. 19:13); de se importar apenas com o seu enriquecimento imoral (șee ehă), derramar sangue inocente (dām hannāqî) - quando o sangue do necessitado, do pobre, do desprotegido e do fraco lhe deveria ser precioso ( yêkar dāmām be ênāyw, Sl. 72:14) -, praticar a opressão (ha'ōšeq) e a violência (ham ${ }^{e}$ rûșāh). ${ }^{26}$ A total inaptidão e fracasso absoluto de Joaquim no desempenho do officium regis, conspurcado pelos seus actos, são ainda realçados por comparação directa com a rectidão e exemplaridade de seu pai, Josias, que desfrutou a vida, gozou da prosperidade própria da realeza ('âbîkā hălô' 'âkāl wešătā), julgando a causa do pobre e do necessitado (dān dîn 'ānî w'ebyôn, v. 16), realizando a justiça e a rectidão ('āśāh mišpāt ûṣ̣edāqāh), pelo que foi consequentemente bem sucedido ('āz țôb lô, v. 15; 'āz ț̂̂b, v. 16 > LXX).

Por conseguinte, contrariamente a Josias e a Šallum, cujos reinados se viram fatalmente interrompidos por reacção ou intervenção de Necao II (610-595 a. C.) - o primeiro provavelmente executado (2 Rs. 23:29) ${ }^{27}$ o segundo deposto e deportado para o Egipto (2 Rs. 23:33-34) -, e por isso foram lamentados, Joaquim não será lamentado por ninguém (Jr. 22:18), sendo-lhe negados não só os rituais fúnebres comuns - lamentação e sepultamento -, como também os próprios da sua dignidade real e relativos ao sepultamento. Assim, 22:19 proclama que Joaquim receberá a sepultura de um jumento, ou seja, o seu corpo será arrastado e lançado fora das portas de Jerusalém, permanecendo insepulto, uma terrível pena que exprimia a rejeição e desprezo total pelo indivíduo. ${ }^{28}$

17 Apesar da perspectiva preponderantemente crítica e negativa sobre a realeza, Jr. 23:4-5 apresenta um oráculo convencionalmente interpretado sob o prisma messiânico cuja autenticidade e correspondente datação têm dividido os exegetas. ${ }^{29} \mathrm{O}$ profeta anuncia que Yahweh erguerá um rebento justo/legítimo (șemahșaddîq) da estirpe de David que reinará 
como rei, prosperará, executará o direito e a justiça ('āśāh mišpāt ûș dāqāh) na terra e será desse modo chamado "Yahweh é a nossa rectidão/justiça" (yhwh șidqēnû, v. 6), aç̧ão divina em flagrante contraste com a rejeição de Joaquin (Jr. 22:30).

Por fim, importa mencionar acepções que o lexema mišpāt assume isolada ou pontualmente na tradição jeremiana. Na contexto da acção simbólica envolvida na compra do campo em Ănātôt, Haname'el suplicava a Jeremias, seu primo, que the adquirisse o seu campo em conformidade com a prioridade que o direito de posse e

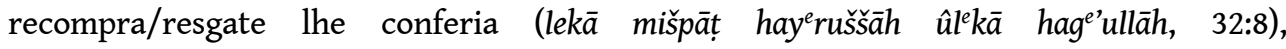
provavelmente enquanto familiar mais próximo de Haname'el (vd. Lv. 25:25 ss.). Para além de "direito" - acepção que poderá ser mais frequente em Jr. do que a superfície dos textos aparenta, particularmente em relação ao termo ș̣edāqāh -, mišpāt poderá assumir ainda, em Jr. 8:7, um significado sapiencial ligado à percepção da ordem do mundo através da observação da obra da criação e dos seus ritmos naturais perpétuos: as aves

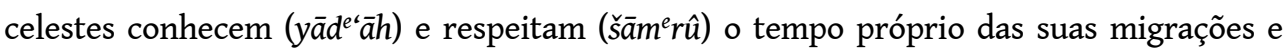
ritmos naturais, mas o povo não conhece surpreendentemente a ordem/decreto de Yahweh (mišpāt yhwh).

\section{Conclusões: apontamentos para uma hermenêutica histórica do conceito de justiça em Jeremias}

19 Apesar de tudo, é possível afirmar que a temática da justiça social acaba por ocupar uma posição algo lateral na intervenção profética de Jeremias no contexto da sociedade hierosolimita dos finais do período monárquico. Em várias instâncias, contrariamente a Mq. (2:2; 3:1-3, 9-11; 6:10-12; 7:3-4, 6), as críticas carecem de alguma especificidade sociológica e histórica, limitando-se a invocar a observância de normas morais ou práticas sociais genéricas, consignadas pela tradição e pelo direito consuetudinário (vd. Ex. 22:13-16, 21-24; 23:1-9. Dt. 24:14-15, 17), ${ }^{30}$ contra uma diversidade de situações de exploração ou precariedade socioeconómica, desenraizamento social e risco de marginalização (estrangeiro, órfão, viúva, oprimido, diversos níveis de pobreza, etc.).

A exortação ao cumprimento da justiça, quer enquanto rectidão, direitura, quer enquanto protecção e restituição dos direitos que se reconhecem próprios de cada indivíduo, e garantia do acesso dos mais desfavorecidos à justiça, denuncia não só a convicção na corrupção dos juízes e na falência dos procedimentos judiciais, mas sobretudo a negligência e fracasso essencial da realeza no desempenho, de dimensão salvífica, da sua função justiceira. Joaquim constitui a este respeito um caso flagrante da inversão do paradigma de realeza, fornecendo, principalmente no ciclo contra a realeza e em Jr. 36, um modelo de anti-realeza que encarna a injustiça e a opressão, o extravio moral e religioso que conduziu Judá à catástrofe ${ }^{31} \mathrm{~A}$ insistência de Jeremias na interpelação da realeza para que cumprisse as suas funções demonstra que o profeta continua a reflectir dentro de um horizonte monárquico, equacionando a realeza como cerne da estrutura social, instituição necessária e dado adquirido na ordem do mundo.

Contrariamente a Dt., que reelabora a globalidade do normativo sócio-religioso no sentido da implementação de uma sociedade ideal e tende a secundarizar o papel do rei (vd. Dt. 17:14-20), a concepção de justiça social presente em Jr. revela ligações íntimas ao iaveísmo hierosolimita, à tradição sapiencial e à ideologia régia consagrada em Sl. 2, 22, 45, 82, 79. Jeremias não procura a implementação de um ideal de igualdade e justiça distributiva, 
mas simplesmente a reafirmação dos princípios morais que devem reger a sociedade e cujo cumprimento assegura a sua conservação e estabilidade, ou seja, a manutenção da ordem imemorial, razoável e divina das coisas inscrita na criação. De facto, segundo Pr. 22:2, o rico ('ǎšrir) e o pobre (rāš) são criação de Yahweh ('ōoséh kullām yhwh); do mesmo modo, Pr. 14:31 pressupõe que Yahweh é o criador ('óséh) do pobre e do necessitado, cuja protecção honra a divindade. Ser justo e recto significa, por conseguinte, conservar e perpetuar esta ordem, prevenindo, corrigindo e punindo os seus desvios. A ordem do mundo, neste sentido, compreende intrinsecamente a existência de assimetrias na distribuição da riqueza e no acesso à participação política. Fracos e fortes, ricos e pobres, senhores e servos constituem elementos integrantes de uma ordem divinamente estabelecida.

É possível sugerir, assim, que a interpretação do conceito de justiça social em Jr. não deva ser forçosamente produzida à luz de uma presumível reforma ou Código Deuteronómico (Dt. 12-26), ainda que este incorpore e elabore legislação presente no Código da Aliança (Ex. 20:22-23:33). Pesem embora todas as reservas que a intervenção editorial/redaccional deuteronomista possa levantar, a tradição profética de Am., Mq. e Is., assim como a tradição sapiencial de Sl. e Pr., no âmbito do iaveísmo hierosolimita e da ideologia real davídica, providenciam um repositório heurístico e um enquadramento interpretativo cuja utilização deverá ser considerada preferencial.

\section{NOTAS}

1. Ao enfatizar a dimensão social da construção do conceito de justiça, não se pretende menosprezar a importância do sujeito e nomeadamente dos processos cognitivos subjectivos no desenvolvimento da moralidade (vd. Lourenço, Eduardo, Psicologia de Desenvolvimento Moral. Teoria, dados e implicações, reimp. da 3. a ed., Coimbra, Almedina, 2006).

2. Digesta I.1.1.10 (Kruger, Paul; Mommsen, Theodor, Corpus Iuris Civilis, vol. 1, Dublin / Zürich, Weidmann, 1973). Este princípio era já de alguma forma reconhecido por Cícero, c. 44 a. C., no seu tratado sobre os deveres. Para o autor, um dos fundamentos da rectidão ou honestidade (omne quod est honestum) era precisamente dar a cada um o que lhe é devido (tribuendoque suum cuique). De Officiis, London / New York, William Heineman / The MacMillan Co., 1913.

3. O Conto do Camponês Eloquente, estabelecido nos finais da XII Dinastia (1939-1760 a. C.), revela bem a agudeza intelectual com que as elites letradas egípcias foram capazes de reflectir criticamente sobre as contradições da justiça divina e humana. De notar, na oitava petição (B1,320-357), a insistência do camponês incógnito na perversão dos juízes e a sua convicção na observância imperiosa da maât, enquanto princípio regulador imanente que garante a efectuação, no caso pendente, de uma justiça comutativa ou correctiva (vd. Canhão, Telo Ferreira, «O Conto do Camponês Eloquente», Cadmo, 16, 2006, pp. 11-54).

4. Assmann, Jan, Maât, l'Egypte pharaonique et l'idée de justice sociale, s. 1., Julliard, 1989. Carreira, José Nunes, Filosofia antes dos Gregos, Mem Martins, Publicações Europa-América, pp. 72-78.

5. Caramelo, Francisco, A Linguagem Profética na Mesopotâmia (Mari e Assíria), Cascais, Patrimonia, 2002, p. 117. 
6. Olmo Lete, Gregorio del, Mitos y Leyendas de Canaan. Según la tradición de Ugarit, Madrid, Ediciones Cristiandad, 1981.

7. Caramelo, ibidem, p. 116.

8. Códigos legales de tradición babilónica, ed. e trad. de Joaquin Sanmartín, Madrid / Barcelona, Trotta / Edicions de la Universitat de Barcelona, 1999.

9. Vd. Albertz, Rainer, A History of Israelite Religion in the Old Testament Period, vol. 1, Louisville, Westminster / John Knox Press, 1994, pp. 163-175. Gonçalves, Francolino, «Os profetas hebraicos e a política do seu tempo», Cadmo, 2, 1992, pp. 16-59. Sicre Díaz, José Luis, Profetismo en Israel. El Profeta. Los Profetas. El Mensaje, 7.. ed., Estella, Verbo Divino, pp. 142-148. Idem, Los Dioses Olvidados. Poder y riqueza en los profetas preexilicos, Madrid, Ediciones Cristiandad, 1979.

10. Na sua análise crítica sobre o ciclo literário contra os reis (Jr. 21:11-23:6), Carroll notava que a dinâmica conflitual entre profetismo e realeza constituía um paradigma de interacção transversal à História Deuteronomista e ao corpus profético (Carroll, Robert P., From Covenant to Chaos. The Uses of Prophecy in the Book of Jeremiah, London, Xpress Reprints, 1996, pp. 136-137), naquilo que será provavelmente a imposição de uma visão teologicamente modelada e retroprojectada da história de Israel. A imposição dessa estrutura interpretativa à representação do passado visaria, em parte, explicar os motivos da catástrofe que atingiria Judá nos inícios do século VI a. C., insistindo na culpabilização da monarquia e no papel admonitório e regenerador do profetismo, e justificando, em última instância, o fracasso dessa intervenção divinamente ordenada (Jr. 25:4-14).

11. Mander, Pietro; Durand, Jean-Marie, Mitología y Religión del Oriente Antiguo, vol. 2, Barcelona, Editorial Ausa, 1995, pp. 309-313.

12. A data tradicionalmente atribuída à morte de Josias e à ascensão de Joaquim é 609 a. C. Contudo, alguns autores defendem que a morte de Josias e a ascensão de Joaquim devem ser datadas de 610 e 609 a. C., respectivamente (vd. Hooker, Paul K.; Hayes, John H., «The Year of Josiah's Death: 709 or 610 BCE?», in The Land that I Will Show You. Essays on the History and Archaeology of the Ancient Near East in Honour of J. Maxwell Miller, ed. de J. Dearman e M. Graham, Sheffi eld, Sheffield Academic Press, JSOTSS 343, 2001, pp. 96-103. Miller, J. Maxwell; Hayes, John H., A History of Ancient Israel and Judah. 2. ed., Louisville / London, Westminster John Knox Press, 2006, pp. 460-461).

13. Efectivamente, a relação entre a família textual massorética e a da Septuaginta (LXX), e o valor heurístico dos respectivos testemunhos, assim como a historicidade e fiabilidade do relato de 2 Rs. 22-23 sobre o reformismo josiano, e a questão da relação entre Jeremias e o Deuteronómio têm suscitado uma grande diversidade de respostas por parte dos investigadores. Vd. Leuchter, Mark, Josiah's Reform and Jeremiah's Scroll: Historical Calamity and Prophetic Response, Sheffi eld, Sheffield Academic Press, 2004. Sweeney, Marvin, King Josiah: The Lost Messiah of Israel, Oxford, Oxford University Press, 2001. Carroll, Robert P., Jeremiah, London / New York, T \& T Clark, 2004. Sharp, Carolyne, Prophecy and Ideology in Jeremiah. Struggles for Authority in the Deutero-Jeremianic Prose, London / New York, T \& T Clark, 2003, pp. 157-169. Para a história redaccional da tradição jeremiana, em particular, vd. Albertz, Rainer, Israel in Exile. The History and Literature of the Sixth Century B.C.E., Atlanta, Society of Biblical Literature, 2003, pp. 303-345.

14. Sobre o significado e utilização destes termos no corpus veterotestamentário, vd. Bovati, Pietro, Re-Establishing Justice. Legal Terms, Concepts and Procedures in the Hebrew Bible, Sheffi eld, Sheffield Academic Press, JSOTSS 105, 1994, pp. 172-211. Weinfeld, Moshe, «Justice and Righteousness הקָָדִצִ - The Expression and its Meaning», in Justice and Righteousness. Biblical Themes and their Influence, ed. de Henning Reventlow e Yair Hoff man, Sheffield, sheffield Academic Press, JSOTSS 137, 1992, pp. 242-246.

15. Vd. McKane, William, A Critical and Exegetical Commentary on Jeremiah, vol. 1, Edinburgh / New York, T \& T Clark, 2001, pp. 134-135. Holladay, William, Jeremiah 1, Philadelphia, Fortress Press, 
1986, pp. 193-194, 198-199. Lundbom, Jack, Jeremiah 1-20, New York / London / Toronto / Sydney / Auckland, AB 21A, 1999, 409-410.

16. $\mathrm{TM}=$ texto massorético.

17. Frymer-Kenski, Tikva, «Israel», in A History of Ancient Near Eastern Law, ed. de Raymond Westbrook, vol. 1, Leiden / Boston, Brill, Hdo 72, 2003, pp. 986-987. Vd. Fox, Nili Sacher, In the Service of the King. Officialdom in Ancient Israel and Judah, Cincinnati, Hebrew Union College Press, 2000, pp. 150-154, 158-164.

18. $O$ v. 1 e parte do v. 2 estão ausentes de LXX e constituem inserções secundárias com o intuito de criar um cabeçalho para o conjunto de oráculos subsequente (Tov, Emanuel, The Greek and the Hebrew Bible. Collected Essays on the Septuagint, Leiden / Boston / Köln, 1999, p. 366).

19. Is. 28:16 exprime exemplarmente esta confiança: "Por isso, assim disse o Senhor Yahweh: 'Eis que sou aquele que assentou em Sião uma pedra fundacional, uma pedra pesada, uma pedra angular preciosa, uma fundação segura. Aquele que confia não fugirá [hamma'ămîn lō' yāḥ̂îs]"' (Vd. Dekker, Jaap, Zion's Rock-Solid Foundations. An Exegetical Study of the Zion Text in Isaiah 28:16, Leiden / Boston, Brill, OS 54, 2007, pp. 124-144). Jerusalém constituía evidentemente o axis mundi do iaveísmo hierosolimita e da teologia real davídica: Jerusalém era de facto a "cidade do Grande Rei" (qiryat melek rāb, Sl. 48:3), que aí tinha o seu "palácio" (hêkal, Jr. 7:4); uma cidade estabelecida por Yahweh para sempre ('ělōhîm yekôn nehā 'ad 'ôlām, Sl. 48:9). Vd. Albertz, ibidem, 1994, pp. 117-122, 129-138. Gonçalves, Francolino, "Yahvé, su pueblo y los demás pueblos en el Antiguo Testamento", in Radicalidad evangélica y fundamentalismos religiosos, ed. de G. Tejerina Arias, Salamanca, Publicaciones Universidad Pontificia, 2003, pp. 143-150.

20. Bovati, ibidem, pp. 185-188.

21. A formulação destas infracções morais não depende necessariamente de Ex. 20:13-16 e Dt. 5:17-21, na medida em que a ordem diferenciada pela qual as faltas são enunciadas em Jr. poderá signifi car que a sequência interna, o conteúdo e a forma do Decálogo não tinham sido ainda fixados (vd. Carroll, Robert P., Jeremiah, vol. 1, Sheffi eld, Sheffield Phoenix Press, 2006, p. 209). A referência à prestação de sacrifícios a Ba'al, ou pelo menos a sequência w'ehālōk 'ahărêe 'ẹlōhîm

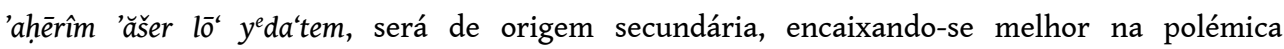
deuteronomista contra a idolatria (McKane, ibidem, p. 163).

22. De acordo com 2 Rs., Necao II investiu Joaquim no trono de Judá e impôs sobre o reino vassalo um oneroso tributo de cem talentos de prata e um talento de ouro (= TM; recensão luciânica de LXX e Pešitta registam cem talentos de ouro). Joaquim recolheu o tributo exigido recorrendo ao aumento da pressão fiscal sobre a propriedade fundiária, i.e., sobre o povo da terra ('am hā'āreș), uma medida profundamente impopular que terá concitado oposição e agitação sociopolítica no início do seu reinado, e que colaborará certamente na explicação da atitude francamente negativa que Jeremias e os redactores deuteronomistas nutriam por Joaquim. A sua governação poderá ter assumido um aspecto particularmente severo, autoritário e intolerante para com qualquer forma de contestação, como sugerido, por exemplo, pela perseguição, extradição e assassínio do profeta Urias a mando do rei (Jr. 26:20-23).

23. McKane, ibidem, lxvii-lxviii, 514-517. Holladay lança igualmente dúvidas sobre a natureza primária da unidade redaccional, acabando no entanto por concluir, em paralelo com 7:3-7, pela sua autenticidade (Holladay, ibidem, pp. 580-582).

24. McKane, ibidem, p. 516. Lunbdom, ibidem, p. 119.

25. Vd. Seitz, Christopher, Theology in Conflict. Reactions to the Exile in the Book of Jeremiah, Berlin / New York, Walter de Gruyter, 1989, p. 93.

26. Em linha com LXX, phónon, "assassínio", "massacre", "carnificina”, embora as versões gregas de Aquila e Símaco apresentem drómon, "corrida" (vd. aparato crítico da Biblia Hebraica Stuttgartensia [BHS], 5. ed. corrigida, s.l., Deutsche Bibelgesellschaft, 1997, p. 825. Field, Frederick, Origenis Hexaplorum, t. II, Oxford, Clarendon Press, p. 629), o que leva Lundbom, apoiado nalguns paralelos jeremianos, a traduzir o termo por "corrida", "correria", "maneira de correr", 
enfatizando a fuga do rei perante as suas responsabilidades (Lundbom, Jack R., Jeremiah 21-36, New York / London / Toronto / Sydney / Auckland, Doubleday, AB 21B, 2004, p. 140).

27. Tanto a lectio grega, como a hebraica não implicam uma leitura bélica do encontro entre Josias e Necao II. De facto, TM relata que Josias, quando Necao II se encontrava em trânsito para o Eufrates, foi ao seu encontro (wayēlek [hammelek > LXX] yōšiyyāhû liqerā'tô [= LXX apantên]), e que Necao o mandou executar (way ${ }^{e}$ mittēhû) quando o viu. Vd. Na'aman, Nadav, Ancient Israel and its Neighbors. Interaction and Counteraction, Winona Lake, Eisenbrauns, 2005, pp. 381-384. Cogan, Mordechai; Tadmor, Hayim, II Kings, New Haven / London, Yale University Press, AB 11, 2008, pp. 291, 301. Talshir, Zipora, "The Three Deaths of Josiah and the Strata of Biblical Historiography (2 Kings XXIII 29-30; 2 Chronicles 20-5; 1 Esdras I 23-31)”, in Vetus Testamentum, vol. 46, n.․ 2, 1996, pp. 215-218.

28. A ausência de rituais fúnebres elementares - lamentação e sepultamento - significava a aplicação de uma prática execratória que, não reconhecendo simbolicamente a defunção do indivíduo, o relegava à errância pela terra, privando-o da possibilidade de uma existência condigna no inframundo. Dt. 28:26, na secção de bênçãos e maldições que encerra o Código da Aliança, ameaça os que desobedecerem à lei com a privação de sepultura, servindo os seus cadáveres de alimento às aves do céu e aos animais da terra, sem que ninguém interfira. Paralelamente, numa fraseologia semelhante, Jr. 16:4 lança a mesma imprecação sobre a população de Jerusalém: as famílias morrerão e não serão lamentadas, nem sepultadas, servindo os seus cadáveres de esterco sobre a terra e comida para as aves do céu e animais da terra.

29. A paronímia com o nome "Sedecias" ("Yahweh é o meu direito") é óbvia e poderia destinar-se tanto a reforçar uma legitimação alternativa e autóctone do rei, cujo nome e legitimidade lhe haviam sido impostas por Nabucodonosor II (Carroll, ibidem, 2006, p. 446-447), como a projectar um modelo de realeza em antítese com a governação ilegítima de Sedecias, explorando de forma messiânica a linha davídida, legítima, de Joaquin (vd. Jr. 52:31-34. Holladay, ibidem, pp. 616-620. Lundbom, 2004, pp. 172-173. Blenkinsopp, Joseph, Une Histoire de la Prophétie en Israël. Depuis le temps de l'installation en Canaan jusqu'à la période hélenistique, Paris, Les Éditions du Cerf, Lectio Divina 152, 1993, p. 220). Job, pelo contrário, assim como Albertz, data a passagem do período pós-exílico e coloca-a no contexto das aspirações reais de Zerubabel (Job, John Brian, Jeremiah's Kings. A Study of the Monarchy in Jeremiah, Aldershot, Ashgate, 2006, pp. 116-117, 128-130. Albertz, ibidem, 2003, p. 314).

30. É difícil precisar até que ponto o direito consuetudinário do Código da Aliança tem uma origem endógena. Segundo Wright, a redacção dessa colectânea terá consistido numa adaptação do direito acádico ao contexto judaíta, entre 740 e 640 a. C., com base num trabalho de adaptação textual intuitiva do Código de Hammurabi (Wright, David P., Inventing God's Law: How the Covenant Code of the Bible Used and Revised the Laws of Hammurabi, Oxford, Oxford University Press, 2009). Similarmente, a infl uência dos modelos e conteúdos legais mesopotâmicos no Código Deuteronómico é desde há muito reconhecida. Römer considera que a redacção da versão primitiva de Dt. (6:4-28) terá utilizado como modelo os tratados de vassalagem de Assaradão (672 a. C.), donde terá extraído secções como 28:20-44 (Römer, Thomas C., The So-called Deuteronomistic History: A Sociological, Historical and Literary Introduction, London / New York, T \& T Clark, 2009, pp. 74-81).

31. Para uma discussão textual e redaccional da representação francamente hostil de Joaquim na tradição textual jeremiana, vd. Job, ibidem, pp. 61-77. 


\section{RESUMOS}

O presente artigo explora as manifestações básicas do conceito de justiça em Jr. 1-25, atendendo à interacção entre justiça social, realeza e profetismo no contexto do Próximo Oriente antigo. É contextualmente analisado o principal léxico pertencente aos campos semânticos da justiça e da injustiça, em sentido estrito, incluindo as categorias sociais directamente envolvidas (estrangeiro, viúva, órfão, pobre, oprimido, necessitado, etc.). Nos termos do iaveísmo hierosolimita e da ideologia régia davídica, Jeremias desenvolve um discurso de denúncia social relativamente genérico sobretudo direccionado para a realeza, exortando-a a cumprir o seu papel de garante do funcionamento e implementação da justiça na sociedade. É contra Joaquim que a polémica jeremiana atinge o seu auge, criando uma imagem de anti-rei que inverte totalmente o paradigma de realeza humana e divina exemplarmente retratada nos salmos reais. 0 direito consuetudinário do Código da Aliança, e sobretudo a tradição profética (Amós, Miqueias e Isaías) e sapiencial (Salmos e Provérbios), e não o Deuteronómio, devem fornecer o quadro interpretativo preferencial para o conceito de justiça social em Jeremias.

The present paper explores the concept of justice within Jer 1-25 regarding the interaction between social justice, kingship and prophecy and the way each one of them is conceptualized in the context of the Ancient Near East. The main terminology is contextually analyzed within the semantic fields of justice and injustice, in a narrow sense, including relevant terms defi ning social groups or status (foreigner, widow, fatherless, poor, oppressed, needy etc.). On the basis of the Jerusalem yahwism and Davidic royal ideology, Jeremiah develops a relatively vague social criticism mainly directed to the Judahite royal house, demanding her to maintain and execute justice in society. It is against Joachim that jeremianic polemics reaches its apex, creating the image of an anti-king which completely reverses the paradigm of earthly and heavenly kingship portrayed in the royal psalms. Customary law from the Covenant Code, and specially the prophetic (Amos, Micah and Isaiah) and wisdom tradition (Psalms and Proverbs), not the book of Deuteronomy, should supply the chief and preferential interpretative framework for reading the concept of social justice in Jeremiah.

\section{ÍNDICE}

Keywords: justice, Jeremiah, social criticism, royalty, Judah, Old Testament

Palavras-chave: justiça, Jeremias, crítica social, realeza, Judá, Antigo Testamento

\section{AUTOR}

\section{JOÃO PEDRO VIEIRA}

Faculdade de Letras da Universidade de Lisboa

Nascido em 1985, licenciou-se em História (ramo científico) pela FCSH da UNL em 2007 e trabalha no Banco de Portugal como técnico de museologia, numismática e notafi lia desde 2008. Pós-

graduou-se em 2009 e prossegue desde então o doutoramento em História Antiga na Faculdade de 
Letras da Universidade de Lisboa (FLUL). A tese de doutoramento em preparação aborda a temática da interação entre profetismo, política e ideologia no Oriente antigo através dos casos de Jeremias e de Muhammad. Foi membro do conselho editorial da Revista Sapiens entre 2009 e 2012. É membro do Centro de História da FLUL.

Born in 1985, graduate in History by the Faculty of Social Sciences and Humanities of the Universidade Nova de Lisboa in 2007, curator in the Bank of Portugal Museum since 2008, postgraduate in Ancient History in the Humanities School of the University of Lisbon (FLUL) in 2009, and since then attending a PhD in Ancient History in the same institution. The PhD thesis under preparation deals with the interaction between prophecy, politics and ideology in ancient Western Asia through the cases of Jeremiah and Muhammad. He was member of the editorial board of Revista Sapiens between 2009 and 2012. Member of the History Centre of FLUL. 